\title{
Fundamentos da concepção tridimensional do direito.
}

\author{
Miguel Reale \\ Catedrático de Filosofia do Direito na Facul- \\ dade de Direito da Universidade de São Paulo \\ - Presidente do Instituto Brasileiro de \\ Filosofia.
}

\section{I \\ Principais teorias Tridimensionais do Direito. Culturalismo e tridimensionalidade}

1. Múltiplas são hoje as teorias que põem em relêvo a natureza tridimensional da experiência juridica, nesta discriminando três "elementos", "fatôres" ou "momentos", (a diversidade dos têrmos já denota as diferenças de concepção), usualmente indicados com as palavras fato, valor e norma.

Tal discriminação, implícita em tôda e qualquer concepção culturalista do Direito, encontra a sua fonte imediata nas obras de Emil Lask e Gustav Radbruch ${ }^{1}$, no que se refere à área do Direito de tradição romanística (Europa continental latino-germânica e tôda a América hibérica) apresentando um desenvolvimento autônomo na América do Norte e na Inglaterra, cujo motivo determi-

1. v. EmIL LAsK, Filosofia Jurídica, trad. de R. Goldschmidt, 1946 (Rechtsphilosophie, 1913); GUSTAV RADBRUCH, Rechtsphilosophie, 1932 (Há tradução portuguêsa dêsse trabalho, com ampla Introdução de CABRAL DE MONCADA, 1937). 
nante talvez se possa encontrar na sugestiva e complexa obra de Roscoe Pound ${ }^{2}$.

2. Do vivo contraste entre jusnaturalistas, empenhados na fundamentação transcedente dos valores jurídicos, e positivistas, afirmadores da imanência daqueles valores na experiência histórica, resultou a posição dos dois citados mestres da Escola sud-ocidental alemã, cuja solução, em última análise, se caracteriza pela interposição de um terceiro elemento, de ligação, entre realidade $\mathrm{e}$ idealidade, substrato empírico e valor: o domínio da cultura, a que correspondem os juízos referidos a valores.

Dessarte, procuram LASK e RADBRUCH superar a antimonia surgida entre a a-historicidade de um valor transcendente, do qual artificialmente se pretendera deduzir o sistema das normas positivas, e o mero significado contingente do empìricamente individualizado, e, como tal, insuscetível de compreensão de validade universal.

A categoria da cultura, além de permitir a referibilidade do ser ao dever ser (mas não a recíproca conversibilidade, visto permanecer de pé a tese fundamental de Kant sôbre a inviabilidade lógica de passar-se do "ser" ao "dever ser", e ser também impossível pensar-se um "dever ser" que se exaura no mundo do "ser") dava lugar a uma cômoda distribuição de pesquisas entre o filósofo, o sociólogo e o jurista, o primeiro incumbido de estudar a transcendentalidade dos valores jurídicos, ou os valores jurídicos em si mesmos, com a conseqüente redução da Filosofia do Direito a uma Axiologia jurídica fundamental; o segundo com a tarefa de indagar das leis que regem as estruturas e os processos fáticos do Direito, isto é, o Direito como fato social, nos quadros da Sociologia jurídica, subordinada ao método indutivo ou experimental; e o terceiro, finalmente, empenhado na análise do Direito enquanto realidade impregnada de significações normati-

2. Sob o prisma que mais interessa a êste estudo, v. Roscoe Pound, Law and Moral, 1926; Interpretation of Legal History, 1923; An Introduction to the Philosophy of Law, 7. ${ }^{\mathrm{a}}$ ed., 1946. 
vas, segundo os cânones da Jurisprudência ou Ciência do Direito, distinta pela especificidade do método jurídicodogmático ${ }^{3}$.

Desdobra-se, como se vê, na doutrina dos dois mestres germânicos o que denominamos tridimensionalidade genérica e abstrata do Direito, visto como a análise ôntica do fenômeno jurídico os conduz a conceber, abstrata e separadamente, cada um dos três elementos encontrados, correspondendo a cada um dêles, singularmente considerado, respectivamente, um objeto, um método e uma ordem particular de conhecimentos: a ciência integral do Direito seria obtida graças à integração dos três estudos (LASK), ou em virtude da simples justaposição de três perspectivas entre si irreconciliáveis e antinômicas (RADBRUCH).

3. Note-se que também ao pensamento filosóficojurídico italiano não passou desapercebida, de certa forma, a tridimensionalidade do Direito, pelo menos de um ponto de vista pedagógico, com a conhecida divisão da Filosofia do Direito em Gnoseologia, Deontologia e Fenomenologia Jurídicas, como foi admiràvelmente desenvolvida dêsde Icilio Vanni a Giorgio Del Vecchio, e que ainda hoje constitui a orientação prevalecente nesta ordem de estudos ${ }^{4}$.

Não basta porém, distinguir, metodològicamente, as três possíveis tarefas fundamentais da pesquisa jusfilosófica, se não se levar também em conta a tridimensionalidade no plano da Ciência positiva do Direito, ou seja,

3. Para maior esclarecimento dêsse tipo de formulação tridimensional, v. Miguel Reale, Filosofia do Direito, 2. ${ }^{a}$ ed., vol. II, p. 471-473 e 375-478.

4. Cfr. IcILIo VANnI, Lezioni di Filosofia del diritto, Bolonha, 1904, I Parte, Cap. II; GIORGIo DEL Vecchro, Lezioni di Filosofia del diritto, X ed., Milão, 1950, p. 188 e segs., Adolfo RAvà, Lezioni di Filosofía del diritto, Pádua, $3 .^{a}$ ed., vol. I, p. 39 e segs.; Para uma crítica dessa posição v. Felice BatTaglia, Corso di Filosofia del diritto, Roma, 3. ${ }^{2}$ ed., vol. I, p. 18 e segs. 
da experiência jurídica como tal, assim como a correlação dialética que a caracteriza.

De outra forma, aquela distinção apresenta um valor puramente formal ou abstrato, indiferente às co-implicações, por exemplo, da Sociologia Jurídica com a Dogmática Jurídica, sem lhe corresponder uma tarefa efetiva no momento concreto da interpretação e da aplicação do direito.

\section{0 tridimensionalismo na América do Norte.}

4. Na América do Norte e na Inglaterra pode observar-se desenvolvimento análogo nos estudos, embora subordinado a bem diversos pressupostos filosóficos. Nos quadros amplos do naturalismo anglo-americano, - dotado, como se sabe, de características inconfundíveis com as da corrente que na Europa ou na América Latina se costuma designar com o mesmo nome, — é que se veio a sentir a necessidade de uma terceira posição, superadora das antíteses empìricamente surgidas entre a Analytical Jurisprudence, fiel à tradição de JoHn Austin, e as duas outras orientações, também entre si contrastantes, a Ethical Jurisprudence, centrada nas Theories of Justice, de tradição jusnaturalista, e a Historical Jurisprudence, ou a Sociological Jurisprudence, fundadas em não menos relevante tradição, a dos estudos de Sumner MaIne e MaItland.

Foi a abertura do naturalismo a um complexo de outras influências, em função de novas conjunturas históricas, que determinou a progressiva convergência das análises no sentido de uma composição eclética, mais do que para uma síntese, o que, pela primeira vez se observa, como já dissemos, nos estudos de Roscoe Pound, dos quais derivam concepções expressamente tricotômicas e genéricas, como as de Julius Stone, Cairns ou Friedmann ${ }^{5}$.

5. v. as obras de CArrns, Law and the Social Sciences, 1935; The Theory of Legal Science, 1941 e Legal Philosophy from Plato to Hegel, 
Segundo Roscoe Pound, as diferentes Éscolas de juristas do século passado nada mais fizeram senão considerar elementos distintos da complexa realidade que denominamos Direito. Os adeptos da corrente analítica, escreve êle, cuidaram exclusivamente do corpo dos preceitos estabelecidos, em virtude dos quais um resultado legal definido é ligado a uma definida situação de fato. Os juristas de tendência historicista preocuparam-se mais com as idéias e as técnicas tradicionais, assim como com "costumes" condicionadores de decisões conformes às exigências da vida; e, finalmente, o jurista-filósofo foi tentado a ver mais os fins éticos, as exigências ideais do Direito, o que chamou "lei natural", como padrão de aferição da lei positiva ${ }^{6}$.

Após analisar essas três posições, o antigo mestre de Harvard conclui que os três pontos de vista ("law by enactment", "law by convention" e "law by nature") se completam, reciprocamente, demonstrando o artifício de separações radicais ${ }^{7}$.

É dessa colocação inicial de Roscoe Pound que decorre a concepção de uma Jurisprudência integral, segundo os moldes da que nos é oferecida por Julius Stones, constituída por três ramos distintos, (o filosófico, o sociológico e o analítico) todos devidamente integrados no universo da Ciềncia jurídica.

5. Ao mesmo tempo que se operava essa correlação de estudos ou de perspectivas, foi observado também que,

1949; Julius Stone, The Province and Function of Law, 2.a ed., 1950; e Friedmann, Legal Theory, 2. ${ }^{\text {a }}$ ed., 1949. Sôbre a concepção de Pound e STONE, em confronto com o que êle denomina "fórmula Reale", v. JoSEF L. KUNZ, Sôbre a problemática da Filosofia do Direito nos meados do século $X X$, na "Revista da Faculdade de Direito de São Paulo", 1951 (tradução de estudo publicado na östere Zeitschrift für öffentliches Recht", Viena, vol. IV).

6. Roscoe Pound, Law and Moral, cit., p. 23 e segs.

7. ROSCOE Pound, Op. cit., p. 113 e segs. 
considerado apenas sob o prisma metodológico, o normativismo jurídico puro de HaNs Kelsen não pode deixar de pressupor a prévia discriminação de três objetos de pesquisa, dois dos quais (o filosófico e o sociológico) são por êle excluídos da Ciência do Direito como tal, para reaparecer, porém, em planos distintos, compondo esferas de investigação de natureza e alcance metajurídicos.

STONE viu bem o problema quando aproximou a sua tricotomia à de Kelsen, mas observando desde logo: "Alio intuitu, a divisão Teoria Pura de Direito, Sociologia Jurídica e Filosofia da Justiça já foi claramente estabelecida por Kelsen. Essa é substancialmente a divisão por mim adotada, se bem que Hans Kelsen a faça visando excluir as duas outras do campo da Jurisprudência. Nosso propósito é, ao contrário, regularizar e consolidar o lugar de tôdas as três. O objetivo de Kelsen, ao pôr aquela distinção, tem sido às vêzes desacreditar a Jurisprudência sociológica ou a Teoria da Justiça como campos apropriados de indagação de natureza jurídica" 8 .

Segundo Josef Kunz, poder-se-ia falar, a respeito de H. Kelsen, em tricotomia implícita, ${ }^{9}$ mas talvez seja preferível apreciá-la como tridimensionalidade metodológico-negativa: no seu sistema, com efeito, é apenas a Ciência de Direito, como estudo lógico-sistemático de normas, que possui caráter jurídico, ressalvado sempre o caráter metajurídico tanto da Teoria da Justiça como da Sociologia jurídica.

O tridimensionalismo na cultura hispânica.

6. Se, porém, Kelsen considerava metajurídicos, do ponto de vista estrito da Ciência pura do Direito, tanto a compreensão do filósofo como a do sociólogo, outros autores deram à Reine Rechtslehre um entendimento tal que

8. J. Stone, The Province and Function of Law, cit. p. 30, n. 111.

9. Kunz, loc. cit., p. 23 e 37. 
lhes pareceu possível conciliar o normativismo lógico da Jurisprudência com a Axiologia e a Sociologia jurídicas, o que foi feito de maneiras diversas, mas sempre de modo a se distinguirem três perspectivas, em geral consideradas irredutíveis.

Êsse perspectivismo tricotômico nota-se sobretudo nas obras de L. Legaz y Lacambra e E. García Máynez, ${ }^{10}$ nas quais se percebe a justaposição dos motivos crítico-transcendentais do kelsenismo com pressupostos axiológicos inspirados, não só na Filosofia dos valores, como especialmente na Ética de Max Scheler ou Nicolai Hartmann.

Segundo tal orientação, verifica-se uma aporia entre os três pontos de vista possíveis concernentes ao Direito, chegando Máynez à conclusão de que "não se trata de espécies diversas de um único gênero, nem de facetas diferentes de uma mesma realidade, mas sim de objetos distintos".

A uma tridimensionalidade genérica reduz-se, em última análise, a teoria egológica de Carlos Cossio, que dá à Teoria Pura mero valor de Lógica juridica formal, completando-a com outras ordens de pesquisas, atinentes aos aspectos fático e axiológico, discerníveis no Direito concebido como "conduta em interferência intersubjetiva" 1 .

10. v. de L. LEGAZ Y LACAMBRA, Kelsen, 1933 e Introducción a la Ciencia del Derecho, 1943 e de GáRCIA MáynEz, La Definición del Derecho, Ensayo de Perspectivismo Jurídico, 1948.

11. Em trabalho publicado em La Ley, de 12 de junho de 1956, p. 4, sob o título Las actitudes filosóficas de la Ciencia Jurídica, escreve Carlos Cossro: "Afirmar hoje que o Direito é cultura é referir-se a um lugar comum. Sem embargo, esta verdade ontológica ainda não penetrou no seio da Ciência normativa do Direito, de forma a transmudar conceitos dogmáticos fundamentais dando lugar a uma nova técnica judicial e forense. Afirmar, em consonância com aquela tese, que o Direito se apresenta como fato, como valor e como norma, começa a ser também uma afirmação corrente no campo jusfilosófico. Essa é a palavra de JeROMe HaLL, na América inglêsa: de EdUARDo Garcia MÁYNeZ, na América espanhola; de Miguel ReALe, na América portuguêsa, todos êles verdadeiros príncipes da inteligência em nosso domínio". 
Embora sob influência de outros pressupostos filosóficos ainda podem ser lembrados outros exemplos de tridimensionalidade jurídica genérica, como a de PaUL Roubier e Barna Horvath e, de certa forma, também Norberto Bobbio e Antolisei ${ }^{12}$.

6. Lugar à parte ocupa Recaséns Siches, o qual, através de uma original concepção inspirada nos pressupostos do "raciovitalismo" de ORtega y Gasset, elaborou, inicialmente, um tridimensionalismo perspectivistico, que exerceu larga influência no mundo jurídico latino-americano, para, afinal, dar-me a honra de acolher, integralmente a que denomino "tridimensionalidade especifica", consoante resulta desta precisa explanação:"Esa realidad que constituye el Derecho y que posee la dimensión de referirse a valores, tiene forma normativa. O sea, el Derecho es norma, com especiales características, elaborada por los hombres con el propósito de realizar unos valores."

"En esta concepción, continua RECAsÉns, se conservan las tres dimensiones de las que se ha venido hablando valor, norma y hecho -, pero indisolublemente unidas entre si en relaciones de essencial implicación. El Derecho no es un valor puro, ni es una mera norma con ciertas características especiales, ni es un simples hecho social con notas particulares. Derecho es una obra humana social (hecho) de forma normativa encaminada a la realización de unos valores" ${ }^{13}$.

12. v. Roubier, Théorie Générale du Droit, $2 .^{\mathrm{a}}$ ed., 1951 e Le rôle de la volonté dans la création des droit et des devoirs, in "Archives de Philosophie du droit”, 1958. Cfr. Migued REALE, Filosofia do Direito, cit. vol. II, p. 485 e seg. e 522 e seg.

13. L. ReCaséns Siches, Tratado General de Filosofia del Derecho, 1959 , p. 159 . RECASÉNS adverte, à p. 158, que o direito "consiste $(\ldots$.$) en un objeto que esencialmente contiene los tres aspectos$ intíma e recíprocamente unidos de modo inseparable, según lo ha mostrado certeramente (...) Miguel REALE". 


\section{Tridimensionalidade específica.}

8. Era natural que, em um dado momento dos estudos, parecesse insustentável a posição correspondente a uma concepção tridimensional genérica, ou abstrata, vacilante entre uma justaposição extrínseca de perspectivas e uma confessada antinomia ou aporia entre os três pontos de vistas possíveis sôbre a experiência do Direito.

Foi por volta de 1940 que surgiram as primeiras tentativas no sentido de mostrar-se a ilogicidade das teorias que, apresentando a realidade jurídica como sendo constituída de três elementos, isto não obstante, continuavam a conferir plena juridicidade a cada um dêles, abstraído dos demais: foram as pesquisas de Wilhelm Sauer ${ }^{14}$ na Alemanha, e as minhas no Brasil ${ }^{15}$. Só posteriormente é que se desenvolveu o integralismo jurídico de Jerome Hall ${ }^{16}$, também caracterizado pela afirmação comum de que qualquer pesquisa sôbre o Direito, seja ela filosófica, sociológica ou técnico-normativa, deve ser, necẹssária $e$ essencialmente, tridimensional.

Tal concepção cessa de apreciar fato, valor e norma como elementos separáveis da experiência jurídica e passa a apresentá-los, ou como perspectivas (SAUer e Hall) ou como fatôres ou momentos (REale) inilimináveis do Direito: é o que denominamos de tridimensionalidade específica, sendo que a de SAUER apresenta mais caráter

14. WILHELM SAUER, Juristische Methodenlehre, 1940 e Juristische Elementarlehre, 1944.

15. Miguel Reale, Fundamentos de Direito, 1940; Teoria do Direito e do Estado, 1. ${ }^{\text {a }}$ ed., 1940; 2. ${ }^{\text {a }}$ ed., 1960; Filosofia do Direito, cit.: Aspectos da teoria tridimensional do Direito, 1958.

16. JEROME HALL, Integrative Jurisprudence, in "Interpretations of Modern Legal Philosophies", 1947; Living Law of a Democratic Society, 1949. (Há trad. portuguêsa, com prefácio de PAUlo DouRAdo DE GusMÃo) e Reason and Reality in Jurisprudence, 1958 (Há trad. castelhana de Pedro R. DAvid, 1959). 
estático ou descritivo; a segunda se reveste de acentuado cunho sociológico, enquanto que a minha concepção procura correlacionar dialèticamente os três elementos em uma unidade integrante.

Vê-se, pois, que mesmo o tridimensionalismo específico oferece múltiplas e até mesmo contrastantes formulações, de tal sorte que uma doutrina não pode se distinguir das demais pelo simples afirmar-se de uma tricotomia essencial.

Inegáveis são, todavia, os pontos de contato entre as três concepções, pelo menos quanto ao propósito de não perder jamais de vista os três elementos ou fatôres de que se compõe essencialmente tôda e qualquer experiência jurídica, seja ela objeto de estudo por parte do jurista, do sociólogo do Direito ou do jusfilósofo ${ }^{17}$.

Pode-se dizer que Sauer, fundado na sua teoria da mônada de valor, dá mais realce ao elemento axiológico, ao qual ficam subordinados os outros dois, ao passo que na doutrina de Hall são os elementos valor e norma que acabam subordinados, de certo modo, a uma compreensão fática, embora não empírica, dada a sua afirmação fundamental de que, em sua plenitude, "o Direito é uma coalescência especifica de forma, valor e fato".

II

Tridimensionalidade e Dialética da Polaridade. Problemas prévios

9. Em geral, os tridimensionalistas, quer aceitem ou não esta qualificação, têm-se limitado a afirmar o caráter fático-axiológico-normativo do Direito, sem tirar desta colocação do problema tôdas as conseqüências nela implí-

17. Sôbre as correlações entre a minha teoria e a de HALL, v. o estudo de PeDro R. DAvid, Dos concepciones del Derecho integrativas: Hall y Reale nos Anais do III Congresso Brasileiro de Filosofia, 1960. 
citas e que, no meu modo de entender, são do mais alto alcance para a Ciência do Direito, não só para esclarecer e determinar melhor velhos problemas, como também para situar questões novas, reclamadas pelas conjunturas histórico-sociais de nosso tempo.

$\mathrm{Em}$ verdade, assente que seja a natureza essencialmente triádica do Direito, de sorte que a nenhum especialista possa ser dado isolar, de maneira absoluta, um dos fatôres para torná-lo objeto de qualquer pesquisa de ordem jurídica, surgem, desde logo, alguns problemas, a saber:

a) Se há três fatôres correlacionados no Direito, quê é que garante a unidade do processo de elaboração jurídica, e em que essa unidade consiste?

b) Se no Direito há três fatôres, como é que êles se correlacionam, ou, por outras palavras, como atuam uns sôbre os outros? Pode-se falar em fator dominante, que subordine os demais ao ângulo de sua perspectiva?

c) Se todo estudo do Direito é tridimensional, como se distinguirão entre si, respectivamente, as investigações filosófica, sociológica e técnico-formal que tenham por objeto a experiência jurídica?

Da resposta dada a essas perguntas básicas decorrem outras, como, por exemplo, a relativa à possível classificação do saber jurídico, ou mais claramente, das diversas ciências do direito, à luz do tridimensionalismo, com uma distinção dos estudos segundo os diversos planos e âmbitos de pesquisa, o transcedental (filosófico) e o empíricopositivo ${ }^{18}$.

18. Sôbre a classificação tridimensional das Ciências do Direito, v. Miguer Reale, Aspectos da Teoria Tridimensional, cit. e as precisas e esclarecedoras páginas de RECAsÉns Siches em seu Tratado, cit., p. 160-163. Quanto à classificação tridimensional das Ciências Políticas, v. Miguel Reale, Teoria do Direito e do Estado, 1960, Apêndice. 
10. Enquanto que Jerome HaLl opta por uma solução unitária e indiferençada, afirmando que não há senão uma Ciência do Direito, a Integrative Jurisprudence, da qual resultariam várias aplicações técnicas ou artísticas, não obstante terem como único objeto um determinado e distinto "tipo de conduta" 19, penso que o saber jurídico não se apresenta, em seu todo, como uma espécie de "scientia omnibus", mas se desdobra em planos lógicos que não podem e não devem ser confundidos (o plano transcendental e o empírico-positivo) sendo que, em cada um dêsses planos, se discriminam âmbitos ou esferas distintas de pesquisa, que dão título de autonomia, por exemplo, à Sociologia do Direito, à Política do Direito, à Ciência Dogmática do Direito, à História do Direito e às diversas partes em que se desenvolve a Filosofia Jurídica.

O Direito é, por certo, um só para todos os que o estudam, havendo necessidade de que os diversos especialistas se mantenham em permanente contato, suprindo e completando as respectivas indagações, mas isto não quer dizer que, em sentido próprio, se possa falar numa única Ciência do Direito, a não ser dando ao têrmo "Ciência" a conotação genérica de "conhecimento" ou "saber", suscetível de desdobrar-se em múltiplas "formas de saber", em função dos vários "objetos" de cognição que a experiência do Direito lògicamente possibilita.

19. Escreve HALL: "If there is only one knowledge of science of law, there is only one subject matter that constitutes law. The jurisprudential problem is to discover and describe that subject matter, and also to reduce verbal difficulties regarding it. The subject matter is actual positive law, which I have described as a type of conduct that is distinctive in its expression of legal ideas. It is, in other words, the subject matter of the empirical legal scientist" (Reason and Reality in Jurisprudence, cit. p. 394).

o jurisfilósofo norteamericano completa seu pensamento sôbre a unidade da Ciência do Direito: "If there is only one science of law, it follows that the various specialists have drawn upon particular parts of it which, for good reason, they have emphasized or supplemented" (loc. cit., p. 395). 
A unidade do Direito é uma unidade de processus, essencialmente dialética e histórica, e não apenas uma distinta aglutinação de fatôres na conduta humana, como se esta pudesse ser conduta jurídica abstraída daqueles três elementos (fato, valor e norma) que são o que a tornam pensável como conduta e, mais ainda, como conduta jurídica. Não se deve pensar, em suma, a conduta como uma espécie de morada que acolhe três personagens, pois a conduta, ou é a implicação daqueles três fatôres, ou não é nada, confundindo-se com qualquer forma de atividade psico-física indiferençada.

Quando falamos em conduta jurídica não devemos, pois, pensar em algo substancial ou de "substante", capaz de receber os timbres exteriores de um sentido axiológico ou de uma diretriz normativa: ela é, ao contrário, conduta jurídica enquanto e na medida em que já é dotada daquele sentido e daquela diretriz, ou seja, enquanto se revela fático-axiológico-normativa.

\section{Natureza dialética da integração jurídica.}

11. Que o Direito seja fato histórico-cultural eis um ponto com o qual estou de pleno acôrdo: mas, é fato histórico-cultural, ou produto de vida humana objetivada, sòmente enquanto o factum do homem se integra normativamente no sentido de certos valores.

Ora, essa unidade de processus encontra, a meu ver, a sua raiz e fundamento na análise mesma do homem e de sua radical polaridade e historicidade.

Se pensarmos em tudo o que o homem, através do devir histórico-social, veio constituindo e realizando, em obras e em atos, teremos a "dimensão objetiva do próprio homem", o que se sói denominar mundo histórico, espírito objetivo, mundo cultural, ou que melhor nome tenha.

Parece-me que se poderia falar em "intencionalidades objetivadas". Cada um e todos os bens culturais - desde 
os mais vulgares até às supremas criações da arte, da ciência e da religião, - possuem uma natureza binada: são enquanto devem ser, (realidades referidas a valores), $\mathrm{e}$, por conseguinte, existem tão sòmente na medida em que valem para algo. O valor peculiar a tais entes é, no entanto, um valor reflexo, visto pressuporem a intencionalidade axiológica do homem como agente da história.

A historiografia é o espêlho no qual o homem temporalmente se contempla, adquirindo plena consciência de seu existir, de seu atuar. Qualquer conhecimento do homem, por conseguinte, desprovido da dimensão histórica, seria equívoco e mutilado. $O$ mesmo se diga do conhecimento do Direito, que é uma expressão do viver, do conviver do homem.

Pensar, porém, o homem como ente essencialmente histórico é afirmá-lo como fonte de todos os valores, cujo projetar-se no tempo nada mais é do que a expressão mesma do espírito humano "in acto", como possibilidade de atuação infinita $e$ livre.

12. A história é, em verdade, impensável como algo de concluído, mera catalogação morta de fatos de uma humanidade "passada", pois a categoria do passado só existe enquanto há possibilidade de futuro, o qual dá sentido ao presente que em passado se converte. $O$ presente, como tensão entre passado e futuro, o "dever ser" a dar pêso e significado ao que se é e se foi, leva-me a estabelecer uma correlação fundamental entre valor $\mathrm{e}$ tempo, Axiologia e História.

Ora, como já disse, o mundo da cultura, - enquanto se apresenta como um patrimônio de atos objetivados no tempo, ou se traduz em "acúmulo de obras", -- é o mundo das intencionalidades objetivas, sendo, como tal, reflexo e segundo, mas e se apresenta sob outro prisma se através das obras procuramos redescobrir o ato criador ou demiurgo, o espírito como liberdade constitutiva da história, e, então, se chega à conclusão primordial de que, dentre todos os entes, sòmente o homem, de uma forma originá- 
ria e fundante, é e deve ser, e, mais ainda, que o ser do homem é o seu dever ser.

O revelar-se do homem a si mesmo já é em si e por si um valor, a fonte de todos os valores. O ser do homem é, repito, de maneira originária, e não derivada, o seu dever ser. E se no chamado "mundo da cultura" há análoga integração fático-axiológica, é porque o homem o constitui "à sua imagem e semelhança"...

13. Assim como, no plano gnoseológico, sujeito e objeto se implicam e se correlacionam, ontognoseológicamente, sem que um têrmo possa ser reduzido ao-outro, e sem que, ao mesmo tempo, um dêles seja pensável sem o outro, (polaridade gnoseológica entre subjetividade e objetividade) da mesma forma o homem, na raiz de seu ser histórico, é enquanto deve ser, mas jamais a sua existência esgota as virtualidades de seu projetar-se temporalaxiológico, nem os valores são concebíveis estrapolados ou abstraídos do existir histórico (polaridade ética entre ser e dever ser) ${ }^{20}$.

É dessa correlação e implicação de caráter bipolar que surge e se constitui o devir histórico, cuja unidade é, pois, dialética ou de processus, cada valor se atualizando em

20. Impossível, na brevidade destas páginas, sintetizar meu pensamento sôbre o que denomino ontognoseologia e dialética da polaridade. Cfr. Miguel Reale, Filosofia do Direito, 2.a ed., 1957 (há trad. italiana de Bagolini e Riccr, G. Giappichelli, Editore, Turim, 1956) e Para um criticismo ontognoseológico, em "Horizontes do Direito e da História", 1957.

A polaridade, quer no plano gnoseológico, quer no plano ético, resolve-se em um processo dialético unitário de implicação e polaridade: a análise fenomenológica do ato cognitivo ou da ação prática revela-nos a polaridade entre teoria e prática, como têrmos que se correlacionam: é tal implicação que condiciona transcendentalmente a unidade dialética do espírito, como tal incompatível com o divórcio feito por KANT entre a instância teorética e a instância prática.

É através da dialética da polaridade que, a meu ver, será possível restabelecer a co-implicação entre "experiência gnoseológica" e "experiência ética", reclamada pela unidade fundamental do espírito. 
momentos existenciais que não exaurem os motivos axiológicos, mas antes põem a exigência de sempre renovadas experiências de valores.

Pois bem, entre as modalidades ou espécies dessas experiências está a do Direito, que, por conseguinte, é tridimensional, como tudo que é cultural, como tensão entre factum e valor, tensão que se expressa na objetividade das normas.

A tridimenssionalidade da conduta ética especifica-se, pois, como tridimensionalidade da conduta jurídica, o que exclui a possibilidade de reduzir-se o Direito a um ordenamento lógico-formal.

\section{Por um normativismo jurídico concreto.}

14. Assente o caráter dialético, de implicação e polaridade, que governa a projeção de valores no factum da experiência jurídica, refletindo-se em sucessivas objetividades normativas, já está aberto o caminho para a resposta à segunda pergunta formulada no parágrafo nove dêste trabalho.

Se a unidade é dialética, ela se desdobra em momeníos, valendo por sua unidade e em sua unidade, sem que qualquer dos fatôres possa ser considerado prevalecente, de maneira absoluta.

De maneira relativa, porém, pode-se dizer que para o jurista, enquanto jurista, o momento culminante é o normativo: a norma jurídica, contudo, não será jamais compreendida integralmente apenas sob seu aspecto formal de proposição lógica, (embora possa e deva ser estudada, por abstração, pela Lógica Jurídica formal) pois ela envolve, necessária e concomitantemente, uma referência tensional aos dados de fato e às exigências axiológicas que lhe deram vida, assim como às intercorrentes ou sucessivas implicações fático-axiológicas que lhe alteram o significado. Essa a razão pela qual o normativismo jurídico, compatível com a minha concepção tridimen- 
sional do direito, é, frize-se bem, um normativismo concreto, e não um normativismo abstrato e formal ${ }^{21}$.

Sob o prisma da Jurisprudência ou Ciência Jurídica, o direito deve ser visto como norma sim, mas desde que se a considere uma unidade integrante e dialética de fatos e valores. Cada norma jurídica traduz a solução ou a composição tensional que, no âmbito de certa conjuntura histórico-social, foi possível atingir entre exigências axiológicas (ideais políticos, centro de interêsse, pressões ideológico-econômicas, valorações jurídicas, morais, religiosas, etc.) e um dado complexo de fatos.

Desnecessário é dizer que a norma jurídica não brota do fato graças a um processus de revelação imanente, como ocorre com as leis físico-naturais explicativas dos fenômenos, as quais são, no fundo, como já foi dito com acêrto, "o retrato sintético do fato". As normas jurídicas, longe de serem mera captação do que no fato já se contém, envolvem uma tomada de posição opcional e constitutiva por parte do homem, à vista do fato e segundo critérios de valor irredutíveis ao plano da faticidade. A norma é, pois, sintese superadora que traduz, não um direito ideal ou mais perfeito, mas apenas o Direito positivo ou posttivável, em função de valorações prevalecentes em dado meio social.

Como, porém, após a emanação da norma, prosseguem as experiências axiológicas, operando-se mutações maiores ou menores na tábua dos valores ou na sua incidência e compreensão particular, e como, concomitantemente, se verificam alterações contínuas nas situações fáticas, mister é reconhecer que a norma jurídica permanece sempre em estado tensional: a sua realizabilidade (e, desde JHERING se diz que a realizabilidade é da essência do Direito) implica uma contínua referência às conexões fático-axiológicas já vividas, bem como a novas conexões fáticoaxiológicas inerentes ao devir histórico.

21. v. nosso trabalho: $A$ crise do normativismo $e$ o normativismo jurídico concreto, em "Aspectos da teoria tridimensional do Direito", cit.. 
Em suma, na concepção tridimensional dialético-integrante do Direito, - que é a correspondente a meu pensamento, - a norma jurídica:

1) assinala um momento conclusivo, mas particular, visto se achar inserida em um "processus" sempre aberto à superveniência de novos fatos $\mathrm{e}$ novas valorações;

2) não tem significação em si mesma, como um dado matemático, ou seja, abstraida da experiência (normativismo abstrato) mas vale na funcionalidade dos momentos que condicionam a sua eficácia (normativismo concreto);

3) envolve uma prévia tomada de posição opcional, ou seja numa decisão por parte do Poder, quer se trate de um órgão constitucionalmente predisposto à emanação das regras de direito, quer se trate do Poder difuso no corpo social, como acontece na hipótese das normas jurídicas consuetudinárias;

4) não pode ser interpretada e aplicada como simples proposição lógica: sua estrutura lógico-formal é suporte de significações estimativas, e pressupõe permanente referibilidade ao plano fático;

5) possui uma certa elasticidade, capaz de atender, em maior ou menor grau, às variaçôes fáticoaxiológicas. Quando tal elasticidade se torna incompatível com as mutações processadas no meio social, impõe-se a revogação ou a derrogação da norma por outra mais adequada.

Tais asserçốes equivalem a dizer que a norma jurídica sofre uma alteração semântica, não obstante a inalterabilidade formal de seu enunciado, ou a permanência intocável de sua roupagem verbal: a semântica jurídica, isto é, o estudo das mutações do sentido temporal das regras de direito, é a demonstração cabal de sua natureza integrante e dialética. 


\section{Faticidade e axiologia.}

15. Se para o jurista, enquanto jurista, o Direito se apresenta sub specie normativitatis, o mesmo não acontece segundo outras perspectivas.

Para o sociólogo do Direito, por exemplo, o punctum saliens do processo dialético da positividade jurídica é representado pelo factum da conduta, cuja compreensão reclama, todavia, a referência aos outros dois fatôres, afim de que se possa falar em fato especificamente jurídico, e não de fato genèricamente social: é a tridimensionalidade que explica e legitima a autonomia de uma Sociologia Jurídica no âmbito da Sociologia Geral.

Quando se afirma que a Sociologia Jurídica tem por objeto o estudo do Direito como fato social não se está dizendo outra coisa, mas sem clara consciência teorética. Com efeito, um fato social só pode ser considerado juridico por apresentar algo de específico: a especificidade do "factum juridicum" decorre de sua qualificação normativa, de nexos de imputabilidade, e sua correspondência a interêsses e valores, que se reconhecem merecedores de garantia específica. Se se fizesse total abstração dêsses "elementos de referência", perder-se-ia a nota específica da juridicidade.

Não é, pois, certo dizer que ao sociólogo só interessa a efetividade ou a eficácia do Direito, v. g. o Direito como conduta empiricamente observável: a eficácia, por mais que seja dominante na compreensão do sociólogo, envolve uma correlação necessária com a vigência (qualidade técnico-formal da norma jurídica) e com o fundamento (qualidade axiológica da norma jurídica).

Não se trata, porém, de simples questões de grau, embora evidentemente haja uma diferença também quantitativa, - mas antes de uma diferença de momentos na captação do processo de positivação jurídica, ou de "realizabilidade normativa de valores". 
16. Por outro lado, o cultor da Política do Direito ou Política Legislativa, que procura a vivência dos valores nas conjunturas e contingências espaço-temporais, afim de prover a regra de direito mais oportuna e necessária, em função dos interêsses atuais da comunidade, põe a nota tônica no momento da valoração. O político do Direito não analisa, porém, valores no plano transcendental, mas sim valorações na órbita empírico-positiva, realizando um trabalho de aferição de diretivas axiológicas em função do possível politico.

Com isto se previne o equívoco de pensar que seja sempre de caráter filosófico-jurídico tôda e qualquer consideração do fato jurídico sob prisma axiológico. Uma coisa é o estudo dos valores como "condições transcendentais" da experiência jurídica (plano de pesquisa do filosófo do Direito); outra coisa é a indagação das valorações atuais, ou seja, da vivência psicológico-social de valores na condicionalidade empírica em que o legislador deve se colocar, como intérprete das aspirações coletivas (plano de pesquisa do político do Direito).

Os problemas da Política do Direito, como se depreende do exposto, correspondem, principalmente, aos formulados de lege ferenda, assim como a Ciência do Direito se desenvolve sobretudo de lege lata, pela interpretação, construção e sistematização das regras jurídicas em vigor.

A tarefa da Política do Direito, ponto de intercessão do saber jurídico com o saber político, tem sido, infelizmente, excluída da cogitação científica, tornando-se cada vez mais necessário restabelecer uma tradição de estudos que uma concepção positivista demasiado estreita pensou poder substituir pelas Sociologias Jurídica e Política. Estas, na realidade, fornecem dados e elementos com os quais, em conexão com outros fatôres de ordem psicológica, econômica, etc., o legislador deve orientar-se no ato da emanação da regra jurídica, segundo exigências axiológicas de prudência, de oportunidade e de conveniência, 
tais como se configuram nas diversas conjunturas históricas e mesológicas.

$O$ que motivou o descrédito da antiga Teoria da Legislação, nos moldes das obras clássicas de BENTHAM ou de Filangieri, foi o seu caráter abstrato iluminístico ou moralizante, dada a carência de conhecimentos psicológicos, sociológicos e econômicos sôbre os fatos condicionadores da ação legislativa, como, por exemplo, sôbre a opinião pública, as ideologias, os grupos de pressão, bem como a falta do sentido de síntese que deve possuir quem, no plano da praxis, não cuida genèricamente dos valores, mas sim da problemática dos meios e dos fins, no âmbito de uma determinada convivência e nas coordenadas de uma singular situação histórica.

Se, como disse alhures, o fim é, no fundo, o valor enquanto reconhecido racionalmente como motivo de conduta, a Política do Direito assinala o momento teleológico que prepara e exige a opção por determinada solução legislativa, com exclusão ou preterição de outras vias possíveis, o que tudo implica no estudo objetivo da correlação entre os meios idôneos e os fins reclamados pela coletividade.

Não há, pois, como confundir o plano filosófico do valor, visto como condicionalidade transcedental da experiência ética em sua universalidade, com o plano científico-positivo das condicionalidades empíricas, a que se subordinam processos concretos de valoração, o que quer dizer, de conexões teleológicas que tecem a trama da positividade jurídica.

17. Clara resulta, dessarte, a distinção entre a esfera da Filosofia do Direito, - estudo critico-transcendental das condições lógicas, axiológicas e histórico-culturais, da experiência jurídica, - e o âmbito das diversas ciências ou saberes jurídicos que tratam da experiência jurídica segundo vários critérios empírico-positivos.

Em contraposição, porém, a qualquer discriminaçầo abstrata, penso que, sendo o conhecimento do Direito 
essencialmente tridimensional, o que em cada ciência particular ocorre é o predomínio de determinada perspectiva em função de um dos três elementos apontados, distinguindo-se a indagação também pelo sentido de seu desenvolvimento. Por outras palavras, poder-se-á distinguir entre três sentidos vetoriais de pesquisa, às quais corresponderão distintas exigências metodológicas, a saber:

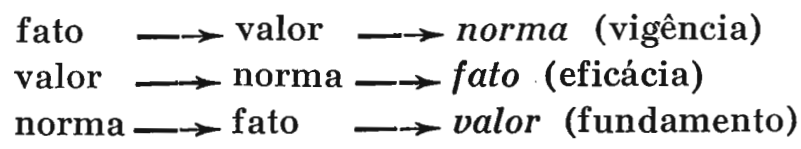

Sob êsse prisma relativo, podemos afirmar que a Ciência do Direito é normativa, visto como suas análises verticalizam-se no momento da normatividade, assim como a faticidade é o momento que interessa prevalecentemente à Sociologia Jurídica. Tais discriminações auxiliam-nos, por outro lado, a repelir a norma juridica como pura categoria lógica, estática, simples juízo caracterizável como hipotético, disjuntivo ou conjuntivo. A norma jurídica é uma entidade histórico-cultural, momento de um processso, que reclama e envolve os outros dois para sua plena compreensão. A Lógica Jurídico-formal diz respeito ao suporte ideal da norma, esclarece-a em seu significado lógico, mas seria equívoco perder de vista a natureza dialética e integrante que lhe é própria.

Desde que, por conseguinte, se tenha sempre presente a impossibilidade de isolar-se qualquer dos três fatôres que compõem o Direito, preservando-se a sua unidade dialética, penso que a tridimensionalidade fornece critérios objetivos para a classificação das formas do saber jurídico, pondo-se um pouco de ordem no "mare magnum" dos estudos pertinentes ao Direito ${ }^{22}$.

22. Sôbre a minha classificação do saber jurídico, segundo critérios tridimensionais, v. a 2.a edição de Teoria do Direito e do Estado, Apêndice, citado. 